\title{
"Educating the Educators: Outreach to the College of Education Distance Faculty and Native American Students"
}

\author{
Tina M. Adams \\ Northern Arizona University \\ R. Sean Evans \\ Northern Arizona University
}

\begin{abstract}
The focus of "Educating the Educators: Outreach to the College of Education Distance Faculty and Native American Students" is to examine and explore the relationship between the Library and the College of Education regarding provision and promotion of Library services to students and faculty taking and teaching classes virtually and at satellite campus and computer lab locations throughout the state. It will include an overview of the special challenges facing the Library in providing these services to a college that offers a large number of distance education classes, enrolls a large number of Native American students, and includes a majority of the institution's distance students and part time distance faculty.
\end{abstract}

Specifically, the presentation will explore four areas:

- The nature of the programs, students and faculty of the College of Education

- The unique conditions under which these courses are offered in rural and reservation locations

- The special conditions of the reservation, including population, economic and educational considerations; and finally;

- How the library's services and promotion efforts have been adapted to be most effective in this unique environment

\begin{abstract}
About Northern Arizona University and our Native American Population
Over the last ten years Northern Arizona University has embraced an ever more aggressive distance education program, serving students primarily in Arizona, but increasingly from an ever growing and diverse array of locations. Initially, NAU undertook this effort by establishing branch campuses around Arizona. Today, looking at the map of NAU IITV and computer lab locations gives an idea of the nature of the program as it was started, and to the extent it still exists today. ${ }^{(1)}$ Early distance education models at NAU made use of local instructors or faculty, or had faculty travel from Flagstaff to the distance sites to teach classes. Today that model still exists, but an ever increasing number of classes are being offered by IITV, and via the Internet. The challenge for the Cline Library historically has been to provide library service to users at a distance regardless of the format of their class. An additional challenge has been to do this for our students who are Native American and participating in classes via sites located throughout their respective Reservations.
\end{abstract}

NAU currently enrolls about 1,343 Native American students as of Fall Semester of 2002, which is about $7 \%$ of the total student population. NAU ranks $4^{\text {th }}$ of all colleges and universities in the nation in total enrollment of Native American students. In addition, NAU is ranked $2^{\text {nd }}$ in the nation for total degrees awarded to Native Americans. A majority of these students are from the Navajo tribe with the Hopi tribe being the next most common. An amazing 65\% of the graduate students in the College of Education are Native American, so it is no 
wonder that one of NAU's primary goals is to be the nation's leading university serving Native Americans. With this goal in mind, the Cline Library's services to this population are vital to the mission of the University. ${ }^{(2)}$

\section{Vital Statistics ${ }^{(3)}$ \\ Educational Enrollment}

In Arizona, there are 1.4 million students over the age of three enrolled in some form of public or private education. This stands against a total population of 5.1 million in the state, or about $27 \%$ of the entire population. The single largest block of students fall into the grade $1-8$, comprising $44.6 \%$ of the total student number. College or graduate school enrollees are next, at $23.6 \%$ of the total student population.

For the Navajo Reservation and Trust Lands area (which includes Arizona, New Mexico and Utah), the total population is 181,269 . Of that number, $39 \%$ of reservation residents over the age of three are enrolled in public or private education The single largest block of students fall into the grade 1-8 category at $53.1 \%$ of the total student number, the next highest numbers are from the grade $9-12$ category with $25.1 \%$ of total. College or graduate school enrollment accounts for only 7,573 students or $10.6 \%$ of the total.

\begin{tabular}{|l|l|lc|}
\hline All students over age 3 & Arizona 1,401,840 & \multicolumn{2}{|l|}{$\begin{array}{l}\text { Navajo Reservation and Trust } \\
\text { Areas 71,172 (\% change } \\
\text { fromArizona) }\end{array}$} \\
\hline Nursery School/Preschool & $81,923 / 5.8 \%$ & $4,062 / 5.2 \%$ & $(-.6 \%)$ \\
\hline Kindergarten & $77,930 / 5.6 \%$ & $3,889 / 5.5 \%$ & $(-.1 \%)$ \\
\hline Elementary School (grades1-8) & $624,766 / 44.6 \%$ & $37,757 / 53.1 \%$ & $(+8.5 \%)$ \\
\hline High School (grades9-12) & $286,122 / 20.4 \%$ & $17,891 / 25.1 \%$ & $(+4.7 \%)$ \\
\hline College, Graduate School & $331,099 / 23.6 \%$ & $7,573 / 10.6 \%$ & $(-13.0 \%)$ \\
\hline
\end{tabular}

\section{Educational Attainment}

In Arizona, for the population over the age of 25 years of age, $26.4 \%$ has had some college education, with the next greatest number, $24.3 \%$ having achieved a High School degree or equivalent. On the Navajo Reservation for the population over 25 years of age, the largest block of that population has achieved a high School degree or equivalent at $26.3 \%$, with the next largest block being those with less than a ${ }^{\text {th }}$ grade education at 24.4 $\%$.

\begin{tabular}{|c|c|c|}
\hline Population over 25 years of age & $\begin{array}{l}\text { Arizona } \\
3,256,184\end{array}$ & $\begin{array}{l}\text { Navajo Reservation and Trust } \\
\text { Areas } 88,662 \text { ( } \% \text { change } \\
\text { fromArizona) }\end{array}$ \\
\hline Less than $9^{\text {th }}$ grade & $254,696 / 7.8 \%$ & $21,612 / 24.4 \% \quad(+16.6 \%)$ \\
\hline $9^{\text {th }}$ to $12^{\text {th }}$ grade, no diploma & $364,851 / 11.2 \%$ & $17,457 / 19.7 \% \quad(+8.5 \%)$ \\
\hline High school graduate & $791,904 / 24.3 \%$ & $23,333 / 26.3 \%$ \\
\hline Some college, no degree & $859,165 / 26.4 \%$ & $15,048 / 17.0 \%$ \\
\hline Associate degree & $219,356 / 6.7 \%$ & $4,748 / 5.4 \%$ \\
\hline Bachelor's degree & $493,419 / 15.2 \%$ & $4,135 / 4.7 \%$ \\
\hline $\begin{array}{l}\text { Graduate or professional } \\
\text { degree }\end{array}$ & $272,793 / 8.4 \%$ & $2,329 / 2.6 \%$ \\
\hline $\begin{array}{l}\text { Percent high school graduate or } \\
\text { higher }\end{array}$ & $81 \%$ & $(-25.1 \%)$ \\
\hline $\begin{array}{l}\text { Percent bachelor's degree or } \\
\text { higher }\end{array}$ & $23.5 \%$ & $(-16.2 \%)$ \\
\hline
\end{tabular}

As we can see, there are many similarities but also some significant differences between these segments of Arizona's populations. Generally, we can see that in comparison with the population of the State ofArizona, residents of the Navajo reservation have significantly lower educational attainment. Despite similar and often greater 
percentages of enrolled students, it can be inferred from this data that enrollment does not necessarily lead to degree completion.

\section{Economic conditions}

Rather than examine the entirety of economic data available from Summary File 3 of the 2000 U.S. Census, we will focus on these key areas: employment and unemployment, and income and industry.

For the State of Arizona, there is a potential labor population of 3,907,229, (comprised of people over the age of 16 years of age); of those $61.1 \%$, are employed. Limiting employment status to just those in the civilian labor force lowers unemployment to $3.4 \%$.

For Arizona $18 \%$ of those employed are working in the education, health and social services industries.

Income for Arizona looks like this: median household income is $\$ 40,558$, median family income is $\$ 46,723$ and per capita income is $\$ 20,275$, with median Male and Female year-round worker incomes being $\$ 35,184$ and $\$ 26,777$ respectively. Poverty status state-wide for families is $13.9 \%$.

For the Navajo Reservation and Trust Areas, the figures shift dramatically. The potential laboring population of this region is 114,966 . Of that number $44.7 \%$ are in the labor force. The percentage of that group that is unemployed is $11.2 \%$. employed.

The percentage of those working work in the Education, health and social services industries is $35.6 \%$ of all

Income for the reservation and trust lands looks like this: Median household income is $\$ 20,005$, median family income is $\$ 22,392$, per capita income is $\$ 7,269$, with full time male and female year-round workers earnings being $\$ 25,667$ and $\$ 20,868$ respectively. Poverty status for families on the Navajo Reservation is $40.1 \%$.

\begin{tabular}{|l|l|lc|}
\hline Population over 16 years of age & Arizona 3,907,229 & $\begin{array}{l}\text { Navajo } \\
\text { and TrustLands } 114,966\end{array}$ \\
\hline Civilian labor force & $2,387,139 / 61.1 \%$ & $51,363 / 44.7 \%(-16.4 \%)$ \\
\hline Employed & $2,366,372 / 60.6 \%$ & $51,330 / 44.6 \%(-16.0 \%)$ \\
\hline Unemployed & $133,368 / 3.4 \%$ & $12,865 / 11.2 \% \quad(+7.8 \%)$ \\
\hline $\begin{array}{l}\text { Education, health and social } \\
\text { service employment }\end{array}$ & $402,183 / 18.0 \%$ & $13,705 / 35.6 \% \quad(+17.6 \%)$ \\
\hline Median household income & $\$ 40,558$ & $\$ 20,005$ & $(-\$ 20,553)$ \\
\hline Median family income & $\$ 46,723$ & $\$ 22,392$ & $(-\$ 24,331)$ \\
\hline Per capita earnings Full-time & $\$ 20,275$ & $\$ 7,269$ & $(-\$ 13,006)$ \\
\hline $\begin{array}{l}\text { Median male full-time } \\
\text { earnings }\end{array}$ & $\$ 26,777$ & $\$ 25,667$ & $(-\$ 9,517)$ \\
\hline $\begin{array}{l}\text { Median female } \\
\text { earnings }\end{array}$ & $\$ 20,868$ & $(-\$ 5,909)$ \\
\hline
\end{tabular}

Clearly we can illustrate two interesting economic realities in examining differences between the state of Arizona and the Navajo reservation. First, there is a huge disparity between the population groups in income which can have far reaching effects regarding what can be done educationally on the reservation. Second, that while the industries surrounding Education, health and social services comprise the single largest block of employers in both the state and the reservation, but that the percentage increase for the reservation population is notable. On the Navajo Reservation education, health and social service jobs account for more $35 \%$ of all available jobs (nearly double the percentage of the state as a whole).

\section{Introduction to the Literature}


There is very little in the library literature regarding library services to Native American populations. What little research that has been done on this topic is no longer current. There are a few useful articles written in the mid 1990's that discuss public library services to this special population, but we have not found anything in the literature regarding academic library services to Native American student populations. ${ }^{(4)}$ Much of what we have included in this paper is experiential and our own assessment although we have drawn on non-library related literature when appropriate.

\section{Nature of the College of Education Program}

The NAU College of Education is offering in Spring 2004 a total of 181 classes, 40 of which are undergraduate. Many of these classes are offered in multiple sections. There are a total of 119 full time on-campus faculty and 484 part-time distance faculty, for a total of 603 Education Faculty. For the purposes of this paper, we will be focusing on those classes offered on the Navajo Reservation, though it is important to note that only $29 \%$ of our Native American student population attends classes via Reservation sites. The majority attend the Flagstaff Mountain Campus. This Spring semester marks a turning point away from reliance on on-site instructors to provide classes locally (3) to instead offering classes via IITV and the Internet ( 9 ). All education classes offered on the reservation for the Spring 2004 semester are graduate level classes.

\section{History of Library Services to Distance Learners at NAU}

In 1987 the Cline Library established the Field Services Office, which served as a reference unit and an interlibrary loan unit for NAU's distance students. As originally configured, Field Services through a variety of means took library services into the field, meaning to places where distance classes occurred. In those days before the Internet, this meant hauling paper copies of indexes and abstracts to the various field sites, and instructing users on how to perform literature searches in these titles. Once students located articles they needed, they contacted the Field Services office which would then obtain copies of materials students needed from the library's periodical collection, or through Interlibrary Loan. The arrival of PC and laptop technology helped in that CD-ROM based databases could be taken and set up at field sites or classrooms for instruction sessions and student use. Field Services duplicated existing library services, but provided them to the distance student population.

Field Services began expanding its role in providing library services, and in the mid-1990s, changing its name to Distributed Library Services to both reflect a change in expansion of services, but also the beginning of its integration into the Cline Library's other units. DLS began by making use of the library's Interlibrary Loan unit to acquire, duplicate and ship materials to distance students rather than performing those tasks within their own unit. DLS was then better able to serve distance sites by focusing on on-site instruction, or distance phone (and later email) reference service. DLS' unique service was gradually being integrated into the library's regular service. Processes were being put in place to ensure that all library users were receiving more equitable treatment and service regardless of their location relative to the University's main campus.

This process accelerated when the library's Reference department began to assist DLS in performing literature searches for students and performing on-site instruction sessions. Meanwhile, the library was also rapidly moving to make more and more of its resources available via the Internet which made mediated searching for students redundant. With the acquisition of more and more on-line, full-text databases, library users were not as reliant upon the library to perform searches, or to fax and mail them articles.

\section{Current Library Services to Distance Learners at NAU}

As has been noted in the previous discussion, historically, the Cline Library has served the needs of distance students via a separate department, Distributed Library Services. However, in 2000 the decision was made by our administration to integrate the Distributed Library Services (DLS) Department into the main Reference Department, the philosophy being that on campus and off campus students should be provided with equitable 
services and served by all staff rather than by a separate department. This philosophy required staff to assume that all students needed the same services, though at times these services may be delivered in different ways.

In the past, DLS had provided what was perceived as separate but equal services by searching for and delivering materials directly to distance students. Pedagogically, this was not sound, as it was discovered that distance students were not gaining the benefit of becoming information literate. A shift in the provision of services occurred which realigned library services and the promotion of information literacy while still providing fast and effective delivery of materials.

To this end, the library's Interlibrary Loan service (now called Document Delivery Services or DDS) moved to a web based request form allowing users to request the Cline Library obtain materials from other libraries from any location. DDS expanded services to include shipping library-owned materials to NAU students living more that 40 miles from campus, thus making our collections available to our distance users in a way similar to our users based on or near campus. DDS had already instituted mailing or faxing of articles directly to users. Electronic delivery of articles had also been added by an initiative out of the Arizona State Library to make use of PCs and scanners to electronically deliver material via the Arial system.

To some extent, through these efforts the library is trying to re-create the traditional role of library as information provider to students and faculty. We know now, and have known for a while that setting distance users adrift to find their research via local libraries or the Internet has not served them well. The academic library's services have become nearly invisible for distance users. It is only through such programs that libraries can bring back and expand their patron base, and provide a quality service to all of their users ${ }^{(5)}$.

The final enhancement to our distance users was the creation of the library's Ask-A-Librarian (AAL) service (www4.nau.edu/library/reference/aal/askalibrarian.asp). While largely just an outgrowth of the e-mail service for distance students, AAL now allows library users on campus, in Flagstaff, or at a distance to use a webbased e-mail form to formulate their reference question, and send it to us at the Reference Desk. As the Reference desk is open and staffed every day (more than 90 hours per week), we guarantee 24 hour response to questions. Those questions which we cannot answer immediately at the desk are referred to other library departments, librarians or subject teams as appropriate. For those more routine questions, we employ a set array of stationeries covering interlibrary loans, renewals, basic research, etc.

The aspect of the service users do not see is the web-based management system created in-house by our Library Technology Services unit that records the question, the user's contact information and status (NAU affiliated or not), and our response to the question. Additional information like time and date of the question and answer, and any referral data are recorded as well. The system allows the user to respond to the quality of the answer they receive by asking them if their question was in fact answered and by permitting them to ask for additional help. As this is an email based system, it is easy to track questions and answers as well as any questions we forward to teams. The system automatically scrubs user information from the database after two weeks, allowing us to keep track of questions and answers- a very useful training and analysis tool. One aspect of the service that needs some mention is the lack of a chat function. At this point AAL has purposely avoided chat. This is based upon a number of factors: service hours, experience with current commercial chat products, and technology issues with distance students.

Many of our students make use of our Ask-A-Librarian email service. We average 200 questions a month via Ask-A-Librarian; this number has been steadily climbing. This is a fairly significant number, considering that NAU is a relatively moderate size university of about 19,000 students. During the last three months that we have kept statistics about our service, as much as $12 \%$ of our reference questions were asked via Ask- A- Librarian. One of the reasons may, of course, be that our turnaround time is, on average, under 2 hours, but the fact that we serve such a far-flung rural population may also account for these numbers ${ }^{(6)}$.

While we do not have any way of knowing whether these numbers include students from the reservation, the high number would indicate that we are probably serving many Native American students with this service. In addition to our Ask-A-Librarian service, we also provide a toll free phone number which anyone may use to call us long distance at no charge and ask a question. 
Because our Ask-A-Librarian service is so successful, it may seem that the obvious next step would be to adopt some of the other electronic reference services such as chat or video conferencing. At this time, we do not have any plans to proceed with new technologies due to cost and the inadequate infrastructure within many of the communities that we serve.

\section{Library Instruction and Native American Distance Learners}

Instruction at distance sites via in-person, IITV and, when necessary, in Internet class-based chat rooms, is vital, especially with regard to some of the special populations we serve off-campus, such as the Navajo and Hopi tribes. It is obvious that instruction is necessary to bridge the skills gap with this population who are less technologically and computer savvy due to more limited access to computers. The Reservation areas are heavily dependent upon the NAU computer labs, which are often shared with and housed in public schools. Due to the infrastructure challenge on the Reservations, these labs are sometimes the only place that people living on the Reservations are exposed to and have the opportunity to use computers.

Instruction sessions held on the Reservation are very well attended. Students there are interested in developing their research skills. But even with such a motivated group of students, there are many challenges to providing services on the reservation. Travel and travel costs are often an issue. Reservation instruction requires the use of a university fleet vehicle and often an overnight stay where lodging and food must be paid for. This can mean up to $\$ 200$ per trip just to send one librarian to do one instruction session. Many of the population centers on the Reservation are more than a hundred miles from the main campus in Flagstaff, so even when an overnight stay is not necessary, librarians must travel part of each day to get to the sites and back. This means leave time for one or more librarians for an entire day. In addition, there is a cost to NAU for use of the computer labs or IITV labs. Obviously, these costs can add up quickly.

As mentioned, the computer labs are often housed in local public schools. Most contain only about 10 computers, are quite small, and may have limited hours of access. Usually there are not enough computers to accommodate an entire class. Three or four Students must share a computer. In addition, sometimes librarians must bring their own equipment such as a laptop and projector because the labs are set up for student use but not for instruction so there is often not an instructor station. Sometimes the equipment and Internet connections are not compatible so the equipment is of no use. Often the only way to conduct an instruction session is for the librarian(s) to walk around, looking over students' shoulders at their computer monitors indicating in steps, "Click here, now, click there." It is also important to supplement the instruction session with a written handout that includes information on access, strategies, and contact information for both students and faculty.

Once the presentation part of the session is over, librarians incorporate hands-on time into the class, so that students can begin their research and consult us with any questions. Often these library instruction classes are three to four hours long, and these students may never see a librarian again while in their program so it is important to use the time well to help students with their immediate need, but to also instill rapport so students will be more likely to contact the library when they need assistance later as well.

Third, as we mentioned before, these students are often less computer savvy due to the lack of computer access and because the average Native American student is older than the traditional non Native American student. Statistically speaking, the majority of Native American college students are 25 years of age or older. Both the age of the students and their lack of advanced computer skills means that the instruction session is more effective if there are two librarians present. In that instance, one librarian can present, while the other assists students individually with keeping up with the instruction session. When the hands-on part of the session begins, the second librarian is indispensable for helping to field questions and assist with individual consultations.

Another consideration when providing instruction to this particular population is cultural awareness and sensitivity. Many of the students that we teach on the Reservation are Navajo, although some are Hopi. We have found that in-person instruction is by far the most effective and culturally respectful form of instruction for this population. Native American students, in general, have expressed a preference for face-to-face instruction. We have found that Native American students often have a fear of asking questions. In addition, as the research on learning styles in Native American populations has shown, these students usually prefer to work in groups, prefer to approach the research in a holistic and global style of organization rather than a linear or sequential approach and learn best 
when material is presented with a visual component, like illustrations, multimedia or other visual aids. In general, Native American students also prefer observational and collaborative activities to lecture and textual learning.

When instructing students from these culture we try to take into account both cultural considerations and learning style preferences. We present the resources so students may observe how to use a particular interface. Then, we allow students to work in groups and have plenty of hands-on free time. At this time in the class, the librarians will visit the groups of students individually. In these smaller groups students generally feel more comfortable asking questions and we are able to answer the more complex questions. Of course, the research and our own experiential observations are all generalizations and there are exceptions. We do not want to imply that all Native American students or even all Navajo students are alike, but through our own experience we have found that these preferences for learning generally hold true for the students we have interacted with.

In addition to the manner of instruction, it is also important that we choose, or make available culturally sensitive materials. For example, in one class involving research relevant to starting a small business, we chose to use a short video in addition to the standard review of finding and using relevant resources. We chose a video that we thought would be engaging and get the students interested. The video contained interviews with successful Native American entrepreneurs who answered insightful questions and gave advice. This was a great hit with the students who remarked that they liked it because it was produced by, for and about Native Americans. When choosing materials it is vital that you not choose condescending materials. This video was relevant and respectful, but not preachy, about what is needed to succeed as a Native American businessperson and had the added benefit of employing the students' preference for visual learning.

Choosing good materials is important, but students must also be made aware of collections that may be of special interest to them. For instance, often the students we instruct on the reservation who are enrolled in the College of Education are majors of our Bilingual and Multicultural Education program. These students find our special collections and archives materials very useful. The Special Collections and Archives at NAU Cline Library collect materials related to the history of the Colorado Plateau region of Northern Arizona. Students studying Bilingual and Multicultural Education through the College of Education can find a rich collection of materials related to Navajo and Hopi culture and history, including materials that are relevant for studying early white motivated "education" programs and the related movement to assimilate Native Americans into white culture.

In another case the library provided culturally relevant materials, via Document Delivery Services (DDS), to a Reservation based IITV class. We worked with the instructor to identify and provide an array of biographies of famous Native Americans. If the library did not have a requested biography, we purchased it on rush order. It cannot be overstated how important it is for libraries to collect and provide culturally responsible materials to support and inform not only our Native American students, but to provide a realistic cultural representation of any ethnic group to all of our students.

Culturally speaking, though in-person instruction is the most effective, it is not the only way in which we instruct students on the reservation. IITV classes broadcast from the home campus to satellite campuses across the reservation are very popular so librarians often attend these classes to teach research skills.

It is no surprise that librarians serving distance students must always be able to adapt. For instance, teaching library skills via IITV can be uncomfortable at first. One must interact with the students via television cameras, be prepared to write down all important information such as web addresses, telephone numbers and other contact information and broadcast it via the pad cam, since students in this environment often prefer visual learning over auditory.

In addition to being comfortable with using a pad cam for writing notes, one must consciously remember to speak clearly and monitor all IITV screens all showing different sites to be aware of students' questions or to notice problems or confusion. One must also be comfortable with being a disembodied voice! Much of the session will be spent showing students how to navigate through the library web page, while the narration goes over the image of the Web page that is being shown on the monitors. 


\section{Internet-based classes and Web instruction tools like WebQuest}

Increasingly, NAU is moving away from IITV classes and even in-person Reservation classes in favor of Internet-based courses. This may have implications for Native American students who generally prefer IITV and inperson classes. In addition, there are a limited number of computers available to Reservation students and some computer skills issues. ${ }^{(7)}$ How all of these factors will affect the way NAU and the Cline Library serves the students on the Reservation remains to be seen, as this is a new direction. However, it is clear that this change will again require librarians who serve off campus students to find viable ways to instruct students at a distance.

One tool that we are in the process of developing and hope will have more instruction application than our current course resource page is the use of Webquest modules. Webquest is still in its infancy at the Cline Library, but may prove to be a tool which can be used to relate the research process to students through sequential modules. We will include illustrations, audio, and video files in these Webquest modules to address students' many learning styles and compensate for the fewer opportunities for in-class library instruction as the University moves increasingly towards web-based teaching in the distance learning environment. At the moment, the library has used subject or class-specific course pages to assist students with locating important resources for a particular class or assignment. Unfortunately, while these course resource pages are very popular and do address many of the needs of our distance learners for easy access to a librarian vetted lists of resources, they are not designed to provide instruction about the research process. ${ }^{(8)}$

\section{Outreach to Faculty and Students}

The library has developed many services for students and faculty in the home campus environment. Because of distances involved, the challenge has been to not only provide these same services equitably to students and faculty at a distance as we have discussed, but to generally increase faculty and student awareness of the services that the library can provide them.

In an attempt to educate faculty about our services the librarians from the Education Team worked with the Assistant Dean of the College of Education and the College's Instructional Designer to arrange the library's involvement in the College of Education Faculty Development Workshop. After our presentation we met individually with interested faculty who wanted to discuss their needs with us one-on-one and arrange appointments.

The challenge is always, of course, enticing the faculty to attend such workshops. Although attendance was less than we had hoped for (only a dozen or so faculty were present), we deemed the workshop a success. Most of the faculty at the workshop subsequently asked for a course resource page, an instruction session or electronic reserve, as a result of the session. Many informed their colleagues who did not attend, who in turn contacted us for assistance. We administered an evaluation tool to the attendees. All of the respondents from the workshop rated the session as "Extremely Useful" with many giving us enthusiastic feedback such as,

"Extremely useful, yes! All of the faculty on campus would benefit by this presentation! People where gracious \& go beyond the call of duty to be helpful! Thanks.

“Excellent Services! Very Impressive!" "I look forward to working with you."

In addition to the on-campus workshop we partnered with the College of Education to provide a workshop for distance faculty. The workshop was a grant funded full-day orientation for part-time distance faculty packed with presenters on various topics of interest to Education faculty. The grant allowed the part-time faculty to travel from all over the state and be provided with lodging to attend the event. As part of the workshop, the College of Education developed a web page to accompany the orientation. The Education librarians arranged to participate by providing a web page to be included on the orientation site and the Assistant Dean of Education offered to present this site at the day seminar. See the web page

at: http://jan.ucc.nau.edu/ rse/LibraryServicesFaculty.html. While, the event was only funded to allow about 60 part-time distance faculty to attend, it was definitely a step in the right direction for addressing the need to inform part-time distance faculty of the services and resources available to them at the home campus. 
Another inexpensive and often used approach to communicating information concerning vital services is via email. While not always a successful way to connect with faculty, it is just one of the many ways that the library attempts to inform faculty of new products or services, as well as frequently reminding faculty of our ability to assist them. We send reminder notices before the beginning of each semester encouraging faculty to contact us for course related assistance. Faculty can request on line course readings, the creation of a course resource web page, or general or assignment driven library instruction on line. The form is available from the library's web site at: http://www.nau.edu/library/services/request/coursesupport.html.

Participation in orientation efforts, campus events and special events held by the College are also approaches used. In the process of getting the word out about the library to the students who attend these events, we also have the opportunity to network and meet some of the faculty in person. Visibility is highly important when trying to promote the library to the campus. When possible, getting on the agenda to present briefly at a college's departmental meetings is also a great way to remain visible and involved.

In addition to these various efforts, we still often rely on print publication materials to publicize the library in the many computer and IITV labs located throughout the reservation and the state. We send current brochures to the labs regularly in an effort to promote our services directly to students at their point of need in the labs. Brochures are also included in a direct mailing from the Graduate College to all new graduate students. We also attend IITV and lab technician orientations to give a brief synopsis of what the library can do for students and all the services available. This is especially important since often students at remote labs will ask the lab technician research questions. We want to give the lab techs a basic understanding of using the library website, but emphasize to them the many ways they can direct students to the library for assistance, such as our toll free reference phone number and our Ask-A-Librarian service.

Much of our outreach efforts are in transition as we shift from an organizational structure based on individual subject specialists supporting a college to a team based approach supporting programs and implementing outreach efforts. We have met formally and informally with small groups of faculty demonstrating our services. We find outreach can occur just as effectively by "word-of-mouth". One faculty member impressed by library support can through their communication with colleagues lead to more interaction between librarians and faculty.

\section{Conclusions}

This paper has explored the unique relationship between the library and the College of Education regarding provision and promotion of library services to students and faculty taking and teaching classes at a distance. We have sought to explain the special cultural, technical and logistical challenges facing the library in providing these services to a college that offers a large number of distance education classes, enrolls a large number of Native American students and includes a majority of the institution's part-time distance faculty. We have shared our efforts formal and informal to address these challenges. We hope these attempts will contribute to anyone serving Native Americans and will further the academic success of Native American students.

\section{Endnotes}

1.) For a map and location guide of NAU Distance sites, see: www.nau.edu/its/swlabs/labinfo.html

2.) For a more complete picture of Native American students and employees at Northern Arizona University, please see the NAU Office of Native American Student Services Report, "Fall 2001 Native American Student and Employee Report." http://www2.nau.edu/nass/

3.) All of the population and occupation information is pulled from the 2000 Census of the United States, specifically from the Summary File 3. This material was acquired from the American Factfinder(http://factfinder.census.gov/home/saff/main.html) Web site. The methodology employed involved collecting from Quick Tables the DP-2 Profile of Selected Social Characteristics 2000, DP-3 Profile of Selected Economic Characteristics 2000, and DP-4 Profile of Selected Housing Statistics for the entire State of Arizona, and the Navajo Nation Reservation and Off-Reservation Trust Land, AZ$\mathrm{NM}-\mathrm{UT}$. 
4.) For a discussion of Public Library services see "Information needs and services of Native Americans." in Rural Libraries Vol. 15, 1995, pp. 37-44. and "Native Americans and library service: Washingtonexamples." in Alki Vol. 11, March 1995, pp. 6-7

5.) Ann Wolpert succinctly describes the situation in her article "Service to Remote Users: Marketing the Library's Role" in Library Trends, Vol. 47 (1), pp. 21-42. Specifically see the section entitled Academic Libraries.

6.) The first assessment of the Ask-A-Librarian service came in April 2003. It confirmed much of what was known about the service, but there were some interesting elements. The report is entitled: An Analysis of the Ask A Librarian Service June 2002 to April 2003. and is available at: http://www4.nau.edu/library/reference/AALReportJune2002toApril2003.htm

7.) Among the unique aspects of the Navajo Reservation is the relative lack of Internet connectivity. This means for many of NAU's reservation based students that their only means of Internet access is at an NAU Computer Lab, or on a PC at one of the public schools. Private PC ownership is not very prevalent as slightly more than $60 \%$ of Reservation residences lack even telephone service according to Census 2000 Summary File 3, DP-4 Profile of Selected Housing Characteristics: 2000. See : http://factfinder.census.gov/home/saff/main.html for additional data.

8.) See: The WebQuest Page at: http://webquest.sdsu.edu/ for more information and samples of WebQuest pages for student use. The essential implication for librarians attempting library research instruction at a distance is the need to find ways to add instructional text to the basic elements of the course pages already offered to replace the lack of in-person instructional opportunities. While the library is currently experimenting with the WebQuest model, it is possible that we may wind up with another product or some sort of hybrid entity.

\section{Bibliography}

American Factfinder, Summary File 3 Quickfiles. Retrieved 17 November 2003 from United States Bureau of the Census, American Factfinder Web Site: http://factfinder.census.gov/home/saff/main.html

An Analysis of the Ask A Librarian Service June 2002 to April 2003. Retrieved 5 December 2003, from Northern Arizona University, Reference Services Web Site: http://www4.nau.edu/library/reference/AALReportJune2002toApril2003.htm

Fall 2001 Native American student and employee report. (2001) Retrieved 3 December 2003, from Northern Arizona University, Planning and Institutional Research Web site: http://www2.nau.edu/nass/

Hilberg, R. Soleste, \& Tharp, Roland (2002). Theoretical perspectives, research findings and classroom implications of the learning styles of American Indian and Alaska Native students. West Virginia: ERIC Digest.

Talakte, Catherine. (n.d.). NAU factbook 2002-2003: Northern Arizona University Student Characteristics, Native American Students Fall 2002. Retrieved 1 December 2003, from Northern Arizona University, Native American Student Services Web site: http://www4.nau.edu/pair/Factbook/2002FactBook/FactBook2002-2003.htm

Wolpert, A. (1998). Service to Remote Users: Marketing the Library's Role. Library Trends, 47, 21-42. 